\title{
Clinical and prognostic significance of aberrant T-cell marker expression in 225 cases of de novo diffuse large B-cell lymphoma and 276 cases of other B-cell lymphomas
}

\author{
Naoko Tsuyama1, Daisuke Ennishi², Masahiro Yokoyama ${ }^{3}$, Satoko Baba ${ }^{4}$, Reimi \\ Asaka $^{1,4}$, Yuko Mishima ${ }^{3}$, Yasuhito Terui ${ }^{3}$, Kiyohiko Hatake ${ }^{3}$ and Kengo Takeuchi ${ }^{1,4}$ \\ ${ }^{1}$ Division of Pathology, The Cancer Institute, Japanese Foundation for Cancer Research, Tokyo, Japan \\ ${ }^{2}$ Department of Hematology, Oncology and Respiratory Medicine, Okayama University Graduate School of Medicine, Dentistry \\ and Pharmaceutical Sciences, Okayama, Japan \\ ${ }^{3}$ Department of Hematology Oncology, The Cancer Institute Hospital, Japanese Foundation for Cancer Research, Tokyo, \\ Japan \\ ${ }^{4}$ Pathology Project for Molecular Targets, The Cancer Institute, Japanese Foundation for Cancer Research, Tokyo, Japan \\ Correspondence to: Kengo Takeuchi, email: kentakeuchi-tky@umin.net \\ Keywords: diffuse large B-cell lymphoma, CD5, CD8, aberrant expression, T-cell marker \\ Received: October 20, $2016 \quad$ Accepted: February 28, $2017 \quad$ Published: March 23, 2017 \\ Copyright: Tsuyama et al. This is an open-access article distributed under the terms of the Creative Commons Attribution License \\ (CC-BY), which permits unrestricted use, distribution, and reproduction in any medium, provided the original author and source \\ are credited.
}

\section{ABSTRACT}

Expression of T-cell markers, generally investigated for immunophenotyping of T-cell lymphomas, is also observed in several types of B-cell lymphomas, including diffuse large B-cell lymphoma (DLBCL). We previously reported that CD5 expression in DLBCL is an inferior prognostic factor in the era of rituximab. However, data regarding the frequencies, histological relevance, and prognostic importance of T-cell markers other than CD5 are currently unavailable. In the present study, we comprehensively evaluated the expression of T-cell markers (CD2, CD3, CD4, CD5, CD7, and CD8) in 501 B-cell lymphomas, including 225 DLBCLs, by flow cytometry and subsequent immunohistochemistry. T-cell markers other than CD5, such as CD2, CD4, CD7, and CD8, were expressed in $27(5 \%)$ patients, and notably, all of these cases were classified as large B-cell lymphoma subtypes: 25 DLBCLs and 2 intravascular large $B$-cell lymphomas. CD5 and other T-cell markers were expressed in $15 \%(31 / 225)$ and $10 \%(25 / 225)$ of DLBCL cases, respectively. Five of them co-expressed CD5 and other T-cell markers. Retrospectively analyzing the prognostic relevance of T-cell markers in 169 patients with primary DLBCL treated with rituximab-based chemotherapy, we showed that only CD5 was a strong predictor of poor survival. This study provides information about the occurrence of T-cell markers other than CD5 in B-cell lymphomas, their frequent histological subtypes, and their prognostic significance in DLBCL. CD5 was reconfirmed as a negative prognostic marker in DLBCL patients receiving rituximab-inclusive chemotherapy, whereas T-cell markers other than CD5 were found to have no impact on clinicopathological and survival analyses.

\section{INTRODUCTION}

Lymphocytes are generally subdivided into B, T, and natural killer cells, depending on their lineage markers: CD19, CD20, CD22, and immunoglobulins for B cells; $\mathrm{CD} 2, \mathrm{CD} 3, \mathrm{CD} 4, \mathrm{CD} 5, \mathrm{CD} 7$, and $\mathrm{CD} 8$ for T cells; and
CD56 for natural killer cells. Lymphoma cells, which are the neoplastic counterparts of lymphocytes, usually retain the lineage marker expression pattern of their normal counterparts. Therefore, lymphomas are subclassified according to the expression pattern of their markers. However, in some lymphomas, aberrant expression of lineage markers is observed. 
CD5 is primarily expressed by T cells, but is also expressed by a small subset of B cells [1]. In B-cell neoplasms, CD5 is usually expressed in chronic/small lymphocytic lymphomas (CLLs/SLLs) and mantle cell lymphomas (MCLs), for which the normal counterparts are considered to be CD5-positive B cells. However, other B-cell lymphomas may sometimes express CD5 aberrantly. Approximately $10 \%$ of the diffuse large B-cell lymphomas (DLBCLs) express CD5 [2, 3], and such cases comprise an immunohistochemical subgroup of DLBCL, according to the $2008 \mathrm{WHO}$ classification [4]. Therefore, CD5-positive DLBCL has been well studied, and some researchers claim that it has a worse prognosis than CD5negative DLBCL $[2,3]$.

In contrast to CD5, the significance of other T-cell markers rarely expressed in B-cell lymphomas remains unclear. Although B-cell lymphomas with T-cell markers other than CD5, such as CD8 ${ }^{+}$CLL [5-13] or CD2/CD3/ $\mathrm{CD} 4 / \mathrm{CD} 7 / \mathrm{CD}^{+}$large B-cell lymphoma [13-31] have been reported (Table 1), data regarding their frequency, histopathological distribution, and clinical features are rarely available, because the number of identified cases in each report is small. This rarity may partly be attributed to the differences in the immunophenotypic procedures used. In immunohistochemistry (IHC), a limited number of lineage markers, such as CD3, CD20, and/or other frequently expressed lineage markers, are usually examined first; other less frequently expressed markers are subsequently investigated for further subclassification. This convention means that once a case is determined to be of B-cell lineage, it may be further examined for other less frequently expressed B-cell markers, but not T-cell markers.

In the present study, we investigated the frequency and histopathological distribution of T-cell marker-positive mature B-cell lymphomas in 501 cases, the largest number so far to be consecutively screened by flow cytometry (FCM). Every T-cell marker-positive case was validated by IHC. We identified 27 cases with T-cell markers other than CD5, and investigated their clinicopathological characteristics. Furthermore, to clarify the clinical relevance of T-cell markers other than CD5 in primary DLBCL, we retrospectively analyzed 169 patients with DLBCL, who received rituximab plus cyclophosphamide, doxorubicin, vincristine, and prednisone (R-CHOP)-based chemotherapy, and follow-up at our institution.

\section{RESULTS}

\section{Frequencies of T-cell marker detections in B-cell lymphomas and correlation with histopathological classification}

Of the 501 mature B-cell lymphoma cases analyzed, 92 cases were positive for T-cell marker(s), including DLBCL-not otherwise specified (DLBCL) $(51 / 225,23 \%)$, MCL (17/17, 100\%), CLL/SLL (13/13, 100\%), marginal zone lymphoma (MZL) (4/81, 5\%; 2 extranodal, 2 nodal), intravascular large B-cell lymphoma (IVLBCL) (2/2, $100 \%$ ), follicular lymphoma (FL) $(1 / 134,0.7 \%)$, and low-grade B-cell lymphoma unclassifiable (4/19, 21\%) cases. After excluding patients with CLL/SLL and MCL (because their cases arise from CD5-positive B-cells by definition), among 62 cases positive for T-cell marker(s), the most frequently expressed T-cell marker was CD5 (n $=43)$, followed by CD8 $(\mathrm{n}=18), \operatorname{CD} 7(\mathrm{n}=10), \operatorname{CD} 2(\mathrm{n}=$ $2)$, and CD4 $(n=1)$ (Figure 1). Eight of these 62 cases were found to express more than one T-cell marker. No CD3positive cases were identified.

T-cell markers other than CD5 (CD8, CD7, CD2, and CD4) were found in 27/501 (5\%) cases, all of which were histologically categorized as large B-cell lymphomas: 25 DLBCL, including one case accompanied by FL grade 3B, and 2 IVLBCL cases (Figure 1 and Table 2). These T-cell markers were detected at a significantly higher proportion in DLBCL than in other common types of B-cell lymphomas (DLBCL vs. FL: 25/225 vs. $0 / 134, p<0.001$; DLBCL vs. MZLs: $25 / 225$ vs. $0 / 81, p$ $=0.001)$. The frequency of CD5 and other T-cell marker detection in DLBCL was 15\% (31/225) and 10\% (25/225), respectively. We observed co-expression of CD5 and other T-cell marker(s) in 5/31 CD5-positive DLBCLs (16\%).

Light chain restriction by FCM was observed in 26/27 B-cell lymphomas positive for T-cell markers other than CD5. Clonal immunoglobulin heavy chain $(\mathrm{IgH})$ rearrangement was found in all of the tested cases (12/12) using Southern blot analysis. Meanwhile, FCM analysis detected no expression of either surface CD3 or T-cell receptor (TCR) $\alpha \beta$. Southern blot analysis detected no clonal TCR gene rearrangement, in all tested cases (Table $2)$. These findings strongly supported the B-cell nature of the 27 cases positive for T-cell markers other than CD5.

\section{Clinicopathological findings for patients with T-cell markers other than CD5}

The clinical data of 27 patients with expression of T-cell marker(s) other than CD5 are presented in Table 3 . The patients included 19 males and 8 females, aged 41- 82 years (median 65.5). Ann Arbor stage III or IV was observed in $14 / 27(52 \%)$ patients. The majority of the cases had extranodal involvement $(24 / 27,89 \%)$. We compared the baseline clinical characteristics of 223 DLBCL patients stratified based on T-cell marker status (Table 4): T-cell marker-negative DLBCL ( $\mathrm{n}=175 ; 78 \%)$, CD5-positive DLBCL ( $\mathrm{n}=31 ; 14 \%)$, and non-CD5-T-cellmarker-positive DLBCL $(\mathrm{n}=17 ; 8 \%)$. Compared to T-cell marker-negative DLBCLs, CD5-positive DLBCLs showed a significant difference in female-male ratio $(p=0.0059)$, poor performance status (PS $>1 ; p=0.0290)$, extranodal involvement ( $p=0.0133)$, and non-germinal center (nonGC) phenotype $(p=0.0043)$. However, between T-cell marker-negative and non-CD5-T-cell marker-positive DLBCLs, no significant differences in any of the clinical parameters were observed. 
Table 1: Non-CD5-T-cell marker-positive large B-cell lymphomas: literature review

\begin{tabular}{|c|c|c|c|c|c|c|c|c|c|c|c|c|c|c|c|}
\hline \multirow{2}{*}{ References } & \multirow{2}{*}{$\begin{array}{l}\text { Total no. } \\
\text { of cases }\end{array}$} & \multirow{2}{*}{$\begin{array}{c}\text { No. of } \\
\text { positive } \\
\text { cases and } \\
\text { subtype }\end{array}$} & \multicolumn{6}{|c|}{ T-cell marker (no. of positive/tested cases) } & \multicolumn{3}{|c|}{$\begin{array}{l}\text { B-cell marker (no. of } \\
\text { positive/tested cases) }\end{array}$} & \multicolumn{2}{|c|}{ Gene rearrangement } & \multirow{2}{*}{$\begin{array}{l}\text { EBER } \\
\text {-ISH }\end{array}$} & \multirow{2}{*}{$\begin{array}{l}\text { Detection } \\
\text { method }\end{array}$} \\
\hline & & & CD2 & CD3 & CD4 & CD7 & CD8 & CD5 & CD20 & PAX5 & CD138 & IGH/K & TCRB/G & & \\
\hline Suzuki et al. & 150 & 11 DLBCL & $4 / 11$ & $0 / 11$ & $1 / 11$ & $6 / 11$ & $2 / 11$ & $1 / 11$ & $10 / 11$ & NA & NA & NA & NA & $1 / 11$ & $\begin{array}{l}\text { FCM with } \\
\text { IHC }\end{array}$ \\
\hline Lee et al. & 1 & $\begin{array}{c}1 \\
\text { DLBCL-E }\end{array}$ & 0 & 1 & 0 & NA & 0 & 0 & 1 & 1 & NA & 1 & 1 & 1 & IHC only \\
\hline \multirow{4}{*}{ Oliveira et al. } & \multirow{4}{*}{16} & $2 \mathrm{PBL}$ & $0 / 2$ & $2 / 2$ & $1 / 2$ & $0 / 2$ & $0 / 2$ & $0 / 2$ & $1 / 2$ & $1 / 2$ & $2 / 2$ & $1 / 1$ & $0 / 1$ & $2 / 2$ & IHC only \\
\hline & & $\begin{array}{l}7 \text { DLBCL- } \\
\text { PCD }\end{array}$ & $0 / 7$ & $7 / 7$ & $2 / 7$ & $0 / 7$ & $0 / 7$ & $0 / 7$ & $7 / 7$ & $7 / 7$ & $2 / 2$ & $7 / 7$ & $0 / 7$ & $1 / 7$ & \multirow{3}{*}{ IHC only } \\
\hline & & $\begin{array}{l}5 \text { DLBCL- } \\
\text { AF }\end{array}$ & $5 / 5$ & $5 / 5$ & $4 / 5$ & $0 / 5$ & $2 / 5$ & $4 / 5$ & $2 / 5$ & $5 / 5$ & NA & $4 / 4$ & $0 / 4$ & $0 / 4$ & \\
\hline & & $2 \mathrm{BL}$ & $0 / 2$ & $2 / 2$ & $0 / 1$ & $0 / 1$ & $0 / 1$ & $0 / 2$ & $2 / 2$ & $1 / 1$ & NA & $0 / 0$ & $0 / 0$ & $0 / 2$ & \\
\hline Sun et al. & 1 & $1 \mathrm{PBL}$ & 0 & 1 & NA & 0 & NA & 0 & 0 & 0 & 1 & NP & NP & 1 & IHC only \\
\hline Sangle et al. & 1 & 1 DLBCL & 1 & 0 & 0 & 1 & 0 & 0 & 1 & 1 & NA & 0 & 0 & 0 & $\begin{array}{l}\text { IHC with } \\
\text { FCM* }^{*}\end{array}$ \\
\hline Wang et al. & 1 & 1 PMLBL & 0 & 1 & 0 & 0 & 0 & 0 & 1 & 1 & 0 & 1 & 0 & 0 & IHC only \\
\hline Suzuki et al. & 1 & $1 \mathrm{PBL}$ & NA & 1 & 1 & NA & NA & NA & 0 & 0 & 1 & 1 & 0 & 1 & IHC only \\
\hline \multirow{2}{*}{ Wang et al. } & \multirow{2}{*}{4} & 2 DLBCL & $1 / 2$ & $2 / 2$ & $1 / 2$ & $2 / 2$ & $0 / 2$ & $1 / 2$ & $2 / 2$ & $2 / 2$ & $0 / 2$ & $2 / 2$ & $0 / 2$ & $2 / 2$ & \multirow{2}{*}{ IHC only } \\
\hline & & $2 \mathrm{PBL}$ & $0 / 2$ & $2 / 2$ & $0 / 2$ & $0 / 2$ & $0 / 2$ & $0 / 2$ & $0 / 2$ & $0 / 2$ & $2 / 2$ & $2 / 2$ & $0 / 2$ & $1 / 2$ & \\
\hline Laurent et al. & 27 & $\begin{array}{l}11 \text { ALK+ } \\
\text { DLBCL }\end{array}$ & $0 / 11$ & $0 / 11$ & $11 / 11$ & NP & $0 / 11$ & $0 / 11$ & $1 / 11$ & NA & $11 / 11$ & $1 / 2$ & NA & NA & IHC only \\
\hline Carulli et al. & 951 & 2 DLBCL & NA & NA & NA & NA & $2 / 2$ & NA & NA & NP & NP & NP & NP & NP & FCM only \\
\hline Tzankov et al. & 1 & $1 \mathrm{PBL}$ & NA & 0 & 1 & NA & NA & NA & NA & NA & 1 & 1 & 1 & 1 & IHC only \\
\hline Tomita et al. & 1 & $1 \mathrm{PAL}$ & 0 & 0 & 0 & 1 & 0 & 0 & 0 & NA & NA & 1 & 0 & 1 & IHC and $\mathrm{FCM}$ \\
\hline Petitjean et al. & 12 & $5 \mathrm{PAL}$ & $4 / 5$ & $4 / 5$ & $1 / 5$ & $0 / 5$ & $0 / 5$ & $0 / 5$ & $3 / 5$ & NP & $1 / 4$ & $1 / 1$ & $0 / 1$ & $5 / 5$ & IHC only \\
\hline Kaleem et al. & 210 & 2 DLBCL & $1 / 2$ & $0 / 2$ & $1 / 2$ & $1 / 2$ & $0 / 2$ & $0 / 2$ & NA & $\mathrm{NP}$ & NP & NP & NP & NP & FCM only \\
\hline Inaba et al. & 128 & $1 \mathrm{DL}$ & 1 & 0 & 0 & 3 & 0 & 0 & $3 / 4$ & NP & NP & NDD & NDD & NP & FCM only \\
\hline Beaty et al. & 1 & $\begin{array}{l}1 \mathrm{HHV}+ \\
\text { DLBCL }\end{array}$ & NP & 1 & NP & NP & NP & $\mathrm{NP}$ & 1 & NP & NP & NP & NP & 1 & IHC only \\
\hline Mori et al. & 1 & $1 \mathrm{PAL}$ & 0 & 1 & 1 & NP & 0 & 0 & 1 & NP & NP & 0 & 0 & 1 & IHC only \\
\hline $\begin{array}{l}\text { Hollingsworth } \\
\text { et al. }\end{array}$ & 3 & $\begin{array}{c}1 \text { IDA } \\
\text { lymphoma }\end{array}$ & 0 & $1 \dagger$ & 0 & 0 & 0 & 0 & 0 & NP & NP & 1 & 1 & 1 & $\begin{array}{l}\text { FCM and/or } \\
\text { IHC }\end{array}$ \\
\hline \multirow[t]{2}{*}{ Present series } & \multirow[t]{2}{*}{501} & $\begin{array}{c}25 \\
\text { DLBCL }\end{array}$ & $2 / 25$ & $0 / 25$ & $0 / 25$ & $10 / 25$ & $18 / 25$ & $5 / 25$ & $25 / 25$ & NP & NP & $11 / 11$ & $0 / 9$ & $0 / 25$ & \multirow[t]{2}{*}{$\begin{array}{l}\text { FCM with } \\
\text { IHC }\end{array}$} \\
\hline & & 2 IVLBCL & $0 / 2$ & $0 / 2$ & $1 / 2$ & $0 / 2$ & $1 / 2$ & $2 / 2$ & $2 / 2$ & NP & NP & $1 / 1$ & $0 / 1$ & $0 / 2$ & \\
\hline
\end{tabular}

*The details of the flow cytometry result are not available; †positive by immunohistochemistry and negative by flow cytometry; $\$$ Cases include one patient with follicular lymphoma grade $3 \mathrm{~B}$ and diffuse large B-cell lymphoma (DLBCL); IGH/K: immunoglobulin heavy chain/kappa light chain; TCRB/G, T-cell receptor beta chain/gamma chain; NA, not available; DLBCL-E, Epstein-Barr virus positive DLBCL of the elderly; DLBCL-PCD, DLBCL with plasmacytic differentiation; DLBCL-AF, DLBCL with anaplastic features; NP, not performed; DL, diffuse large cell lymphoma (classification according to Working Formulation); NDD, not described in detail; IDA lymphoma, immunodeficiency associated lymphoma.

Histologically, all cases with T-cell marker(s) other than CD5 were categorized as large cell lymphomas, and showed atypical large lymphoid cell proliferation with a centroblastic or anaplastic morphology, positive for CD20 (Figure 2). Expression of T-cell markers other than CD5 was successfully detected in 22/27 (81\%) cases using IHC. Non-validated cases were dimly positive in FCM analysis and showed negative or indeterminate staining in IHC analysis (Table 2). The available cytogenetic analyses revealed that their karyotypes were complex with numerical abnormalities (Supplementary Table).

Sequential FCM data were available for 7/27 patients. In four of the patients (cases 8, 9, 15, and 27), concordant positive expression of T-cell marker was shown at different sites and at different times of diagnosis, whereas expression in the other 3 patients (cases 11, 17, and 21) exhibited 
a discrepant pattern. Case 8 , originally presented with IVLBCL in the bone marrow and spleen, had a relapse in the lymph nodes with a DLBCL feature, where expression of CD8 was identified at both diagnosis and relapse. Case 27 was IVLBCL with a leukemic presentation and a similar weak expression pattern of CD4 was identified in the bone marrow and peripheral blood throughout. Case 11, initially diagnosed as FL without T-cell marker, transformed into CD8-positive DLBCL on relapse. In case 17, expression of CD8 was observed at diagnosis, but six months after complete response the disease relapsed as the same abdominal tumor without CD8 expression. Case 21 was originally considered a T-cell marker-negative DLBCL that relapsed in the testis with CD7 expression.

\section{Prognostic significance of T-cell marker expression in 169 patients with DLBCL}

The survival of patients with CD5-positive DLBCL was significantly poorer thanthat of patients with T-cell marker-negative DLBCL (Figures 3: 5-year time to progression (TTP), 47\% vs. 73\%, respectively, $p<0.001$; 5 -year disease specific survival (DSS), 63\% vs. 82\%, respectively, $p=0.03$ ). In contrast, there was no significant difference in progression between non-CD5-T-cell markerpositive DLBCL and T-cell marker-negative DLBCL, suggesting that T-cell markers other than CD5 do not have prognostic impacts in DLBCL treated by immunochemotherapy (Figure 3).

Correlations between survival and basic parameters, including sex, International Prognostic Index (IPI), GC/ non-GC phenotype, and T-cell markers (CD5, CD8, and CD7) are shown in Table 5. CD2 was not included in the univariate analysis because the number of CD2positive patients was very small $(n=2)$. Multivariate Cox regression analysis was performed after excluding patients without T-cell marker expression because the patients in this group almost overlapped with CD5-negative patients. Univariate analysis showed that CD5 expression and high IPI were significant prognostic factors for TTP, progression-free survival (PFS), and DSS. Multivariate analysis revealed that high IPI remained a significant independent factor affecting TTP, PFS, DSS, and overall survival (OS). CD5 expression was significantly associated with shorter TTP $(p=0.01)$.

\section{DISCUSSION}

The present study addressed how frequently T-cell markers were expressed in 501 B-cell lymphoma cases, diagnosed according to the 2008 WHO classification. In all cases, expression of T-cell marker was comprehensively investigated using FCM, and additional IHC analysis was successfully conducted for non-CD5-T-cell marker -positive cases. The expression of T-cell markers other than CD5, including CD8, CD7, CD2, and CD4, was identified in 27 patients, the largest number to date. Notably, all of these non-CD5-T-cell marker-positive cases were large B-cell lymphoma subtypes, which showed a significantly higher incidence than other common subtypes, such as FLs and MZLs. Studies evaluating expression of T-cell marker other than CD5 with a large sample size have been reported, but these results did not represent the demography of non-Hodgkin lymphoma subtypes. Carulli et al [13] reported eight patients with non-Hodgkin lymphoma showing aberrant expression of CD8 in 951 bone marrow samples, but that study was sharply biased in patient selection toward lymphomas with bone marrow invasion, such as CLLs/SLLs. In other studies [13, 17, 18] using more than 100 cases, variable histological classification, not the current WHO criteria, was applied, which does not represent the accurate distribution of non-Hodgkin lymphoma.

As for the prognostic relevance of T-cell marker expression, the present study found that only CD5 was a strong predictor of poor outcome in 169 patients with primary DLBCL, as previously reported [3]. Moreover, between non-CD5-T-cell-marker-positive and T-cell marker-negative DLBCLs, no significant difference in outcome was observed. To our knowledge, no survival data of T-cell marker-positive DLBCL has been presented

T-cell marker positive B-cell lymphomas $(n=62)$

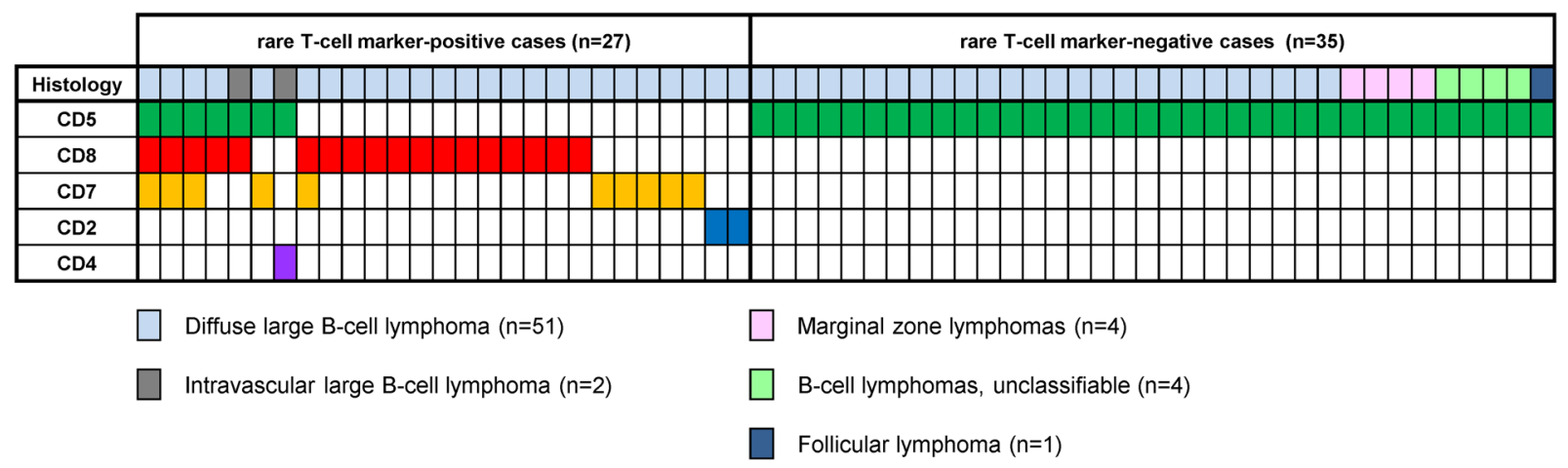

Figure 1: T-cell marker detections in B-cell lymphomas other than CLL/SLL and MCL. Distribution of T-cell markers, including CD5 and other T-cell markers, in 62 cases of B-cell lymphomas other than CLL/SLL and MCL. 
Table 2: Immunohistochemical and molecular findings for 27 patients with non-CD5-T-cell marker-positive B-cell ly mphoma

\begin{tabular}{|c|c|c|c|c|c|c|c|c|c|c|c|c|c|c|c|c|c|c|}
\hline \multirow{2}{*}{$\begin{array}{l}\text { Case } \\
\text { No. }\end{array}$} & \multirow{2}{*}{ Histology } & \multicolumn{9}{|c|}{ Flow cytometry/Immunohistochemistry* } & \multirow{2}{*}{$\begin{array}{l}\text { Cell of } \\
\text { origin }\end{array}$} & \multirow{2}{*}{$\begin{array}{l}\text { Light } \\
\text { chain }\end{array}$} & \multirow{2}{*}{$\begin{array}{l}\text { MYC/ } \\
\text { BCL2 }\end{array}$} & \multirow{2}{*}{ EBER-ISH } & \multirow{2}{*}{$\begin{array}{l}\text { IGH/ } \\
\text { TCR }\end{array}$} & \multicolumn{3}{|c|}{ FISH split assay } \\
\hline & & CD2 & CD3 & CD4 & CD5 & CD7 & CD8 & $\mathrm{CD}^{\prime} \beta^{\dagger}$ & CD20 & CD10 & & & & & & BCL2 & BCL6 & MYC \\
\hline 1 & DLBCL & - & - & - & $\mathrm{ED} /+$ & $\mathrm{EN} /+$ & $\mathrm{ED} /+$ & + & $+/+$ & $-1-$ & GC & $\mathrm{K}$ & $-/+$ & - & $\mathrm{NA} / \mathrm{NA}$ & - & - & - \\
\hline 2 & DLBCL & - & - & - & $-1-$ & - & $\mathrm{D} /+$ & - & $+/+$ & $-1-$ & non-GC & K & $-/+$ & - & $+/-$ & - & - & - \\
\hline 3 & DLBCL & - & - & - & $\mathrm{DN} / \mathrm{I}$ & - & $\mathrm{ED} /+$ & - & $+/+$ & $-1-$ & non-GC & $\mathrm{K}$ & $-/+$ & - & NA/NA & - & - & - \\
\hline 4 & DLBCL & - & - & - & $\mathrm{DN} /+$ & $\mathrm{ED} /+$ & $\mathrm{ED} /+$ & - & $+/+$ & $-1-$ & non-GC & $\Lambda$ & $+/+$ & - & NA/NA & - & + & - \\
\hline 5 & DLBCL $^{\S}$ & - & - & - & $-/-$ & - & $\mathrm{ED} /+$ & - & $+/+$ & $-1-$ & non-GC & $\mathrm{K}$ & $-1+$ & - & $+/ \mathrm{NA}$ & - & - & - \\
\hline 6 & DLBCL & - & - & - & $-1-$ & - & $\mathrm{D} /+$ & - & $+/+$ & $+/+$ & GC & $\Lambda$ & $-1+$ & - & NA/NA & - & - & - \\
\hline 7 & DLBCL & - & - & - & $-1-$ & - & $\mathrm{D} /+$ & - & $+/+$ & $\mathrm{D} /+$ & GC & $\Lambda$ & $+/-$ & - & NA/NA & - & - & - \\
\hline 8 & IVLBCL & - & - & - & $\mathrm{E} /+$ & - & $\mathrm{D} /-$ & - & $+/+$ & $-1-$ & non-GC & K & $-1-$ & - & NA/NA & - & + & NA \\
\hline 9 & DLBCL & - & - & - & $\mathrm{D} /+$ & $\mathrm{DN} /+$ & $\mathrm{DN} /+$ & - & $+/+$ & $+/+$ & GC & $\Lambda$ & $-1+$ & - & NA/NA & - & - & - \\
\hline 10 & DLBCL & - & - & - & $-/-$ & - & $\mathrm{D} /+$ & - & $+/+$ & $+/+$ & GC & $\Lambda$ & $-/+$ & - & $+/-$ & + & + & - \\
\hline 11 & DLBCL & - & - & - & $-1-$ & - & $\mathrm{ED} /+$ & + & $+/+$ & $+/+$ & GC & K & $+/+$ & - & $+/-$ & + & - & + \\
\hline 12 & DLBCL & - & - & - & $-/-$ & - & $\mathrm{D} /+$ & - & $+/+$ & $+/+$ & $\mathrm{GC}$ & $\Lambda$ & $-/+$ & - & $+/-$ & - & + & - \\
\hline 13 & DLBCL & - & - & - & $-1-$ & - & $\mathrm{D} /+$ & - & $+/+$ & $+/+$ & GC & $\mathrm{K}$ & $-/+$ & - & NA/NA & - & - & - \\
\hline 14 & DLBCL & - & - & - & $-1-$ & - & $\mathrm{D} /+$ & - & $+/+$ & $+/+$ & GC & $\mathrm{K}$ & $\mathrm{NA} /+$ & - & NA/NA & - & - & - \\
\hline 15 & DLBCL & - & - & - & $-/-$ & - & $\mathrm{DN} /+$ & - & $+/+$ & $-1-$ & non-GC & $\mathrm{K}$ & $-/+$ & - & $+/-$ & - & - & NA \\
\hline 16 & DLBCL & - & - & - & $-1-$ & - & $\mathrm{E} /+$ & + & $+/+$ & $-1-$ & non-GC & $\Lambda$ & $+/+$ & - & $+/-$ & - & - & - \\
\hline 17 & DLBCL & - & - & - & $-/-$ & - & $\mathrm{E} /+$ & - & $+/+$ & $-/-$ & non-GC & $\mathrm{K}$ & $-/+$ & - & NA/NA & - & - & - \\
\hline 18 & DLBCL & - & - & - & $-1-$ & $\mathrm{E} /+$ & $\mathrm{D} /-$ & - & $+/+$ & $-1-$ & non-GC & $\mathrm{K}$ & $-1+$ & - & $+/ \mathrm{NA}$ & - & - & - \\
\hline 19 & DLBCL & - & - & - & $-/-$ & $\mathrm{D} /+$ & - & $\mathrm{NP}$ & $+/+$ & $-/-$ & non-GC & $\mathrm{K}$ & $+/+$ & - & NA/NA & - & - & - \\
\hline 20 & DLBCL & - & - & - & $-/-$ & $\mathrm{E} /+$ & - & $\mathrm{NP}$ & $+/+$ & $-/-$ & non-GC & $\mathrm{K}$ & $+/+$ & - & NA/NA & - & - & + \\
\hline 21 & DLBCL & - & - & - & $-/-$ & $\mathrm{DN} /+$ & - & $\mathrm{NP}$ & $+/+$ & $-1-$ & non-GC & $\Lambda$ & $-/+$ & - & $+/-$ & - & + & - \\
\hline 22 & DLBCL & - & - & - & $-1-$ & $\mathrm{DN} / \mathrm{I}$ & - & $\mathrm{NP}$ & $+/+$ & $+/+$ & $\mathrm{GC}$ & $\mathrm{K}$ & $+/+$ & - & $+/-$ & - & + & + \\
\hline 23 & DLBCL & - & - & - & $-1-$ & $\mathrm{D} /+$ & - & $\mathrm{NP}$ & $+/+$ & $-1-$ & non-GC & $-\pi$ & $+/+$ & - & NA/NA & - & - & - \\
\hline 24 & DLBCL & - & - & - & $\mathrm{DN} /+$ & $\mathrm{D} /+$ & - & $\mathrm{NP}$ & $+/+$ & $-/-$ & non-GC & $\mathrm{K}$ & $-1+$ & - & NA/NA & NA & NA & - \\
\hline 25 & DLBCL & $\mathrm{D} / \mathrm{I}$ & - & - & $-/-$ & - & - & $\mathrm{NP}$ & $+/+$ & $-1-$ & non-GC & $\Lambda$ & $-1-$ & - & NA/NA & - & - & - \\
\hline 26 & DLBCL & $\mathrm{D} /+$ & - & - & $-1-$ & - & - & $\mathrm{NP}$ & $+/+$ & $-1-$ & $\mathrm{GC}$ & $\Lambda$ & $-1-$ & - & NA/NA & - & - & - \\
\hline 27 & IVLBCL & - & - & $\mathrm{D} / \mathrm{I}$ & $+/+$ & - & - & NP & $+/+$ & $-1-$ & non-GC & $\Lambda$ & $+/+$ & - & $+/-$ & - & + & - \\
\hline
\end{tabular}

$\S_{\text {Case }} 5$ is a patient with DLBCL of the colon associated with an FL grade 3B component in the tonsil. *For T-cell markers other than CD5, the results of immunohistochemistry are given for only flow cytometry positive cases; ${ }^{\circ}$ only the results of immunohistochemistry are given; "absence of expression for both kappa and lambda; IGH, immunoglobulin heavy chain gene rearrangement by southern blot analysis; TCR, T-cell receptor $\beta$ chain gene rearrangement by southern blot analysis; NP, not performed; NA, not available; E, equal; ED, equal to dim; EN, equal to negative; D, dim; DN, dim to negative; I, indeterminate.

in a large number of patients ( $>150$ patients) uniformly treated with R-CHOP-based chemotherapy. Suzuki et al [31] were the first to investigate prognostic implications of T-cell markers other than CD5 in DLBCLs, and they showed that such expression was not associated with outcome, consistent with the present findings. However, in the study by Suzuki et al, [31] the survival data for only 92 patients treated with rituximab-based chemotherapy were available, and the frequency of T-cell marker other than CD5expression was only assessed in the DLBCL population. Additionally, in the survival analysis, only T-cell markers other than CD5 were evaluated, and coexpression of CD5 was not demonstrated. In our study, 5/29 patients with CD5-positive DLBCL simultaneously harbored additional T-cell markers other than CD5, although this redundancy appeared to have little influence on the disease outcome.

CD5-positive DLBCL has been reported, mainly from Japanese cohorts, to have unique clinical features. The present study shared common characteristics with 
Table 3: Clinical characteristics of 27 patients with non-CD5-T-cell marker-positive B-cell lymphoma

\begin{tabular}{|c|c|c|c|c|c|c|c|c|c|c|}
\hline \multirow{2}{*}{$\begin{array}{l}\text { Case } \\
\text { No. }\end{array}$} & \multirow[t]{2}{*}{ Age/sex } & \multirow{2}{*}{$\begin{array}{c}\text { Main } \\
\text { site(s) of } \\
\text { involvement }\end{array}$} & \multirow[t]{2}{*}{ Stage } & \multicolumn{3}{|c|}{$\begin{array}{c}\text { Extranodal } \\
\text { involvement }\end{array}$} & \multirow[t]{2}{*}{ Treatment } & \multirow[t]{2}{*}{ Response } & \multirow{2}{*}{$\begin{array}{c}\text { Follow-up } \\
\text { (months) }\end{array}$} & \multirow[t]{2}{*}{ Status } \\
\hline & & & & $\geq 1$ & $\geq 2$ & BM & & & & \\
\hline 1 & $64 / \mathrm{M}$ & Cecum & IIA & + & - & - & $\begin{array}{c}\text { Sur }+ \\
\text { R-CHOP }\end{array}$ & CR & 68 & Alive, CR \\
\hline 2 & $71 / \mathrm{M}$ & oral cavity & IIA & + & - & - & R-CHOP & NA & 64 & DOD \\
\hline 3 & $77 / \mathrm{M}$ & mediastinum & IVB & + & + & - & R-CHOP & PD & 7 & NA \\
\hline 4 & $66 / F$ & axillary LN & IVB & + & + & - & $\begin{array}{l}\text { R-CHOP } \\
+ \text { RT }\end{array}$ & PD & 24 & $\begin{array}{l}\text { DOD, } \\
\text { refractory }\end{array}$ \\
\hline 5 & $41 / \mathrm{M}$ & tonsil, colon & III & + & + & - & R-CHOP & $\mathrm{CR}$ & 71 & Alive, CR \\
\hline 6 & $44 / F$ & cervical LN & IB & - & - & - & $\begin{array}{l}\text { R-CHOP } \\
+ \text { RT }\end{array}$ & $\mathrm{CR}$ & 53 & Alive, CR \\
\hline 7 & $74 / F$ & oral cavity & I & + & - & - & R-CHOP & $\mathrm{CR}$ & 65 & Alive, CR \\
\hline 8 & $58 / \mathrm{M}$ & BM, spleen & IVB & + & + & + & R-CHOP & $\mathrm{CR}$ & 15 & $\begin{array}{l}\text { DOD, } \\
\text { relapsed }\end{array}$ \\
\hline 9 & $62 / F$ & nasal cavity & IIA & + & - & - & R-CHOP & PR & 34 & $\begin{array}{l}\text { AWD, } \\
\text { relapsed }\end{array}$ \\
\hline 10 & $58 / \mathrm{M}$ & inguinal LN & IVA & + & - & - & R-CHOP & $\mathrm{CR}$ & 52 & Alive, CR \\
\hline 11 & $75 / F$ & abdominal LN & IIIA & + & + & + & R-CHOP & PD & 2 & $\begin{array}{l}\text { DOD, } \\
\text { refractory }\end{array}$ \\
\hline 12 & $60 / \mathrm{M}$ & $\begin{array}{l}\text { maxillary } \\
\text { sinus }\end{array}$ & I & + & - & - & R-CHOP & $\mathrm{CR}$ & 46 & Alive, CR \\
\hline 13 & $81 / \mathrm{M}$ & Orbit & IA & + & - & - & R-CHOP & $\mathrm{CR}$ & 7 & Alive, CR \\
\hline 14 & $67 / \mathrm{M}$ & abdominal LN & IVA & + & + & - & R-ICE & $\mathrm{CR}$ & 47 & Alive, CR \\
\hline 15 & $62 / \mathrm{M}$ & cervical LN & IIIA & - & - & - & R-CHOP & $\mathrm{CR}$ & 71 & $\begin{array}{l}\text { AWOD, } \\
\text { relapsed }\end{array}$ \\
\hline 16 & $60 / \mathrm{M}$ & parotid gland & IIA & + & - & - & R-CHOP & $\mathrm{CR}$ & 17 & Alive, CR \\
\hline 17 & $78 / \mathrm{F}$ & abdominal LN & IV & + & - & - & R-CHOP & $\mathrm{CR}$ & 26 & $\begin{array}{l}\text { AWD, } \\
\text { relapsed }\end{array}$ \\
\hline 18 & $82 / \mathrm{M}$ & nasal cavity & IA & + & - & - & R-CHOP & CR & 45 & Alive, CR \\
\hline 19 & $64 / \mathrm{M}$ & Orbit & IB & + & - & - & R-DHAP & PD & 2 & DOD \\
\hline 20 & $81 / \mathrm{M}$ & $\begin{array}{l}\text { soft tissue } \\
\text { (leg) }\end{array}$ & IVA & + & + & - & R-CHOP & $\mathrm{CR}$ & 40 & $\begin{array}{l}\text { DOD, } \\
\text { relapsed }\end{array}$ \\
\hline 21 & $55 / \mathrm{M}$ & cervical LN & IVA & + & + & - & R-CHOP & $\mathrm{CR}$ & 12 & $\begin{array}{l}\text { DOD, } \\
\text { relapsed }\end{array}$ \\
\hline 22 & $43 / \mathrm{M}$ & Gingiva & IA & + & - & - & R-CHOP & $\mathrm{CR}$ & 60 & Alive, CR \\
\hline 23 & $78 / \mathrm{M}$ & Orbit & NA & + & + & NA & NA & NA & NA & NA \\
\hline 24 & $65 / \mathrm{M}$ & Prostate & IVA & + & + & - & R-CHOP & CR & 49 & Alive, CR \\
\hline 25 & $81 / \mathrm{F}$ & nasal cavity & IIA & + & + & - & R-CHOP & NA & 57 & DOD \\
\hline 26 & $57 / \mathrm{M}$ & cervical LN & IA & - & - & - & $\begin{array}{l}\text { R-CHOP } \\
+ \text { RT }\end{array}$ & CR & 87 & Alive, CR \\
\hline 27 & $73 / \mathrm{F}$ & $\mathrm{BM}$ & IVB & + & + & + & R-CHOP & PD & 10 & $\begin{array}{l}\text { DOD, } \\
\text { refractory }\end{array}$ \\
\hline
\end{tabular}

M, male; F, female; BM: bone marrow; LN, lymph node; Sur, surgery; RT, radiation therapy; CR, complete response; PD, progressive disease; PR, partial response; NA, not available; DOD, died of disease; AWD, alive with disease; AWOD, alive without disease; R-ICE, rituximab plus ifosfamide, etoposide, and carboplatinum; R-DHAP, rituximab plus dexamethasone, cytarabine, and cisplatinum. 
Table 4: Baseline clinical characteristics of 223 patients with DLBCL according to T-cell marker status

\begin{tabular}{|c|c|c|c|c|c|c|c|c|}
\hline \multirow{3}{*}{ Characteristics } & \multirow{2}{*}{ All DLBCL } & \multirow{2}{*}{$\begin{array}{c}\text { T-cell marker- } \\
\text { negative }\end{array}$} & \multicolumn{3}{|c|}{ T-cell marker-positive } & \multirow{3}{*}{$\mathbf{P}_{\dagger}^{\dagger}$} & \multirow{3}{*}{$P \$$} & \multirow{3}{*}{$\mathbf{P} \S$} \\
\hline & & & Total & CD5-positive & Non-CD5-positive & & & \\
\hline & $\mathrm{n}=\mathbf{2 2 3}$ & $n=175$ & $n=48$ & $\mathrm{n}=\mathbf{3 1}$ & $\mathbf{n}=17$ & & & \\
\hline $\begin{array}{l}\text { Median age, } \\
\text { range (yeas) }\end{array}$ & $66,24-95$ & $66,24-95$ & $66,40-86$ & $66,40-86$ & $62,41-81$ & 0.8937 & 0.7627 & 0.9606 \\
\hline Age $>60$ & $154(69 \%)$ & $123(70 \%)$ & $31(65 \%)$ & $22(71 \%)$ & $9(53 \%)$ & 0.4828 & 0.1717 & 1.0000 \\
\hline Sex: male & $120(54 \%)$ & $99(57 \%)$ & $21(44 \%)$ & $9(29 \%)$ & $12(71 \%)$ & 0.1414 & 0.3122 & $0.0059^{*}$ \\
\hline Stage: $3-4$ & $108(48 \%)$ & $83(47 \%)$ & $25(52 \%)$ & $17(55 \%)$ & $8(47 \%)$ & 0.6261 & 1.0000 & 0.5592 \\
\hline $\begin{array}{l}\text { Performance } \\
\text { status }>1\end{array}$ & $22(10 \%)$ & $15(9 \%)$ & $7(15 \%)$ & $7(23 \%)$ & $0(0 \%)$ & 0.2718 & 0.3696 & $0.0290^{*}$ \\
\hline IPI: $3-5$ & $68(30 \%)$ & $52(30 \%)$ & $16(33 \%)$ & $12(39 \%)$ & $4(24 \%)$ & 0.7236 & 0.7817 & 0.3996 \\
\hline LDH $>$ normal & $118(53 \%)$ & $91(52 \%)$ & $27(56 \%)$ & $19(61 \%)$ & $8(47 \%)$ & 0.6278 & 0.8014 & 0.4352 \\
\hline $\begin{array}{l}\text { Extranodal } \\
\text { involvement } \\
>1\end{array}$ & $44(20 \%)$ & $30(17 \%)$ & $14(29 \%)$ & $12(39 \%)$ & $2(12 \%)$ & 0.0689 & 0.7428 & $0.0133^{*}$ \\
\hline $\begin{array}{l}\text { CNS } \\
\text { involvement }\end{array}$ & $9(4 \%)$ & $6(3 \%)$ & $3(6 \%)$ & $3(10 \%)$ & $0(0 \%)$ & 0.4088 & 1.0000 & 0.1376 \\
\hline $\begin{array}{l}\text { non-GC } \\
\text { phenotype }\end{array}$ & $85(38 \%)$ & $58(33 \%)$ & $27(56 \%)$ & $19(61 \%)$ & $8(47 \%)$ & $0.0044^{*}$ & 0.2883 & $0.0043^{*}$ \\
\hline
\end{tabular}

CNS, central nervous system; non-GC, non-germinal center. $\dagger$ T-cell marker-negative DLBCL vs. T-cell marker-positive DLBCL; \$T-cell marker-negative DLBCL vs. non-CD5-T-cell marker-positive DLBCL; §T-cell marker-negative DLBCL vs. CD5-positive DLBCL; *statistically significant $(\mathrm{p}<0.05)$.

previous studies with respect to unfavorable outcome, poor PS, non-GC subtype, extranodal disease, and female predominance. Compared with a large cohort study of Western populations by Xu-Monette et al., [32] the same clinical features as mentioned above were observed, but the present study found higher incidence (15\% vs. $5.5 \%)$ of CD5 expression. This discrepancy may be attributed to difference in detection methods used (FCM or IHC) rather than the difference in genetic background. As described previously [33, 34], involvement of the central nervous system at the diagnosis or relapse was more frequently observed in CD5 positive cases $(3 / 29 ; 10.3 \%)$ than in CD5 negative cases $(5 / 140 ; 3.5 \%)$; however, this difference was not statistically significant ( $p=0.11$ ), probably owing to the small sample sizes.

As results of previous studies are based on the analysis of samples at diagnosis, the transition of T-cell marker expression has not been reported. We studied sequential samples of 7 patients at diagnosis and histologically-confirmed relapse/progression. Four patients presented identical expression of T-cell marker in the two sequential samples, indicating that both samples were clonally related and that the potential to express T-cell markers can be maintained even in different microenvironments. Of the remaining 3 patients, two displayed additional T-cell marker expression in the later samples (case 11, FL transformed; case 21, testicular relapse of DLBCL), probably due to additional genomic or epigenomic alterations. On the other hand, in case 17, expression of T-cell marker completely disappeared at relapse in the same biopsy site, suggesting that subclone(s) with additional alterations were specifically eradicated by chemotherapy, and other subclone(s) or stem line(s) without the alterations survived and predominated. Meanwhile, aberrant expression of T-cell markers is not necessarily a surrogate for the presence of subclones; phenotype plasticity has been well described and is the more probable cause of this phenomenon.

Although the expression of T-cell markers other than $\mathrm{CD} 5$ is uncommon in mature B-cell neoplasms, it has been described previously. The most frequently reported cases have been CD $8^{+}$CLLs, accounting for $0.5-3 \%$ of the total CLLs $[6,7,10-13]$. This frequency is consistent with the present finding that $\mathrm{CD} 8$ was the most frequently expressed marker among T-cell markers other than CD5, even though no $\mathrm{CD} 8^{+} \mathrm{CLLs}$ were found (0/13). The absence of $\mathrm{CD}^{+}$CLLs in the present study might be attributed to the infrequent incidence of CLL in Japan [35]. Other small B-cell lymphomas, such as FL, MZL, LPL, and MCL, express T-cell markers other than CD5 uncommonly [13, 
A
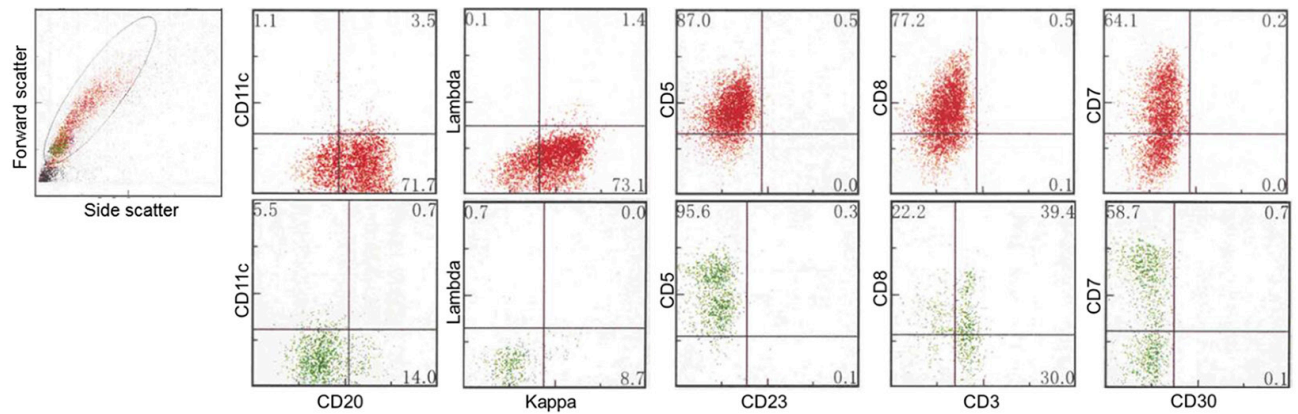

B

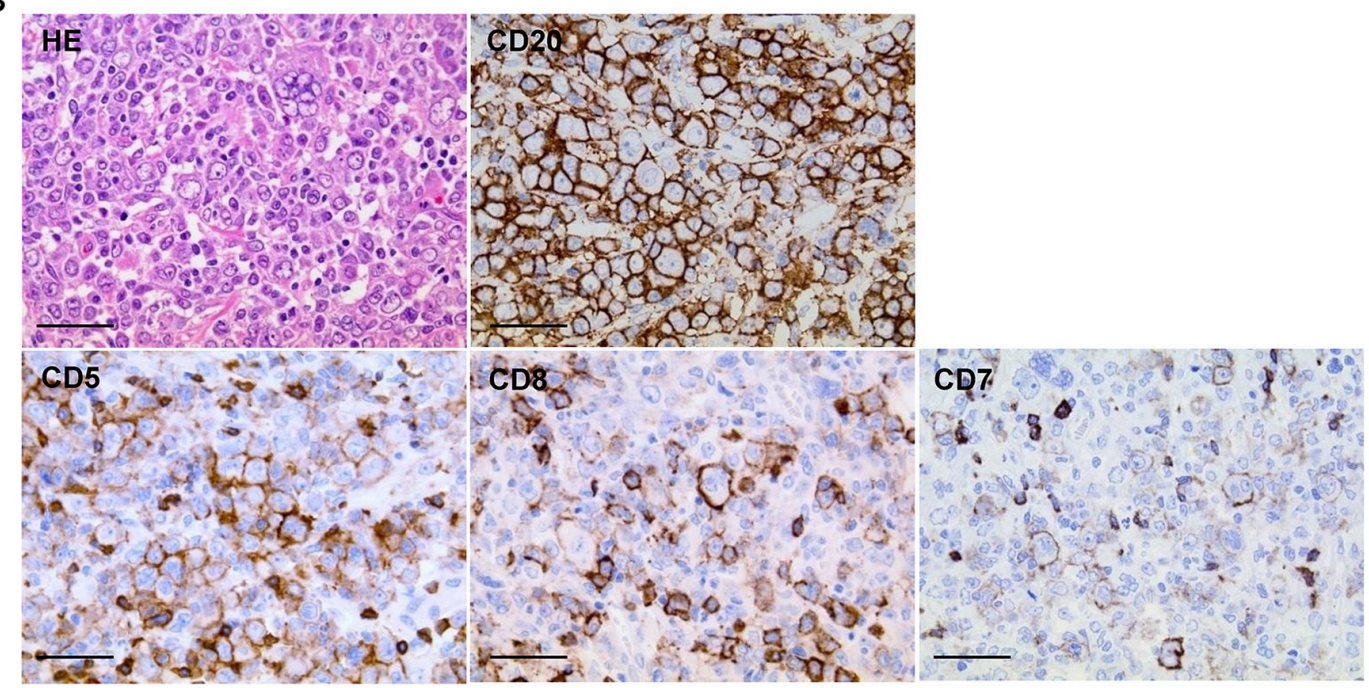

C
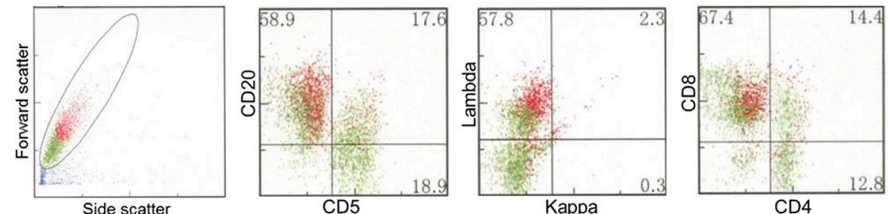

D
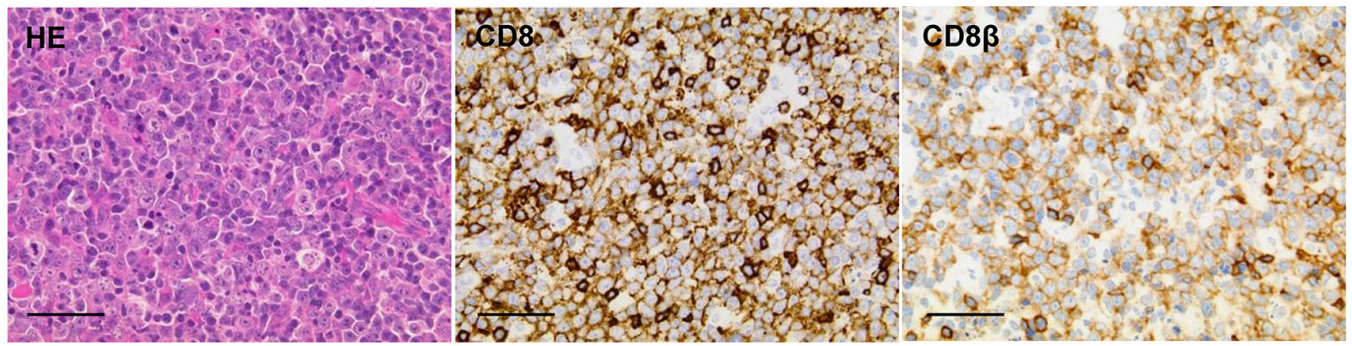

Figure 2: Morphological and immunophenotypic features of T-cell marker-positive diffuse large B-cell lymphomas. A and B, case 1; C and D, case 16. Scale bars represent $50 \mu \mathrm{m}$. (A) Flow cytometry (FCM) showed an abnormal large cell population (red colored plots) positive for CD20, kappa chain, $\mathrm{CD} 5, \mathrm{CD} 8$, and CD7, with a broad range of fluorescent intensity from cells negative or dimly positive for CD7. (B) Histologically, lymphoma cells showed a pleomorphic large cell morphology containing multinucleated giant cells (hematoxylin and eosin stain, HE; $\times 40$ ). Immunohistochemistry showed strongly positive diffuse staining for CD20, weakly positive staining for CD5, and focally positive staining for CD8 and CD7. (C) FCM showed the formation of clusters, with positive staining for CD20, lambda chain, and CD8 (red colored plots). The intensity of CD8 was as strong as that of the background normal T cells (green colored plots). (D) The cell morphology showed centroblastic large cell infiltrates (HE, $\times 60)$. Immunohistochemically, the majority of the lymphoma cells were positive for both CD8 and CD8 $\beta$. Note that the positive staining of T-cell markers on tumor cells was weaker than on admixed normal $\mathrm{T}$ cells, in both case 1 and case 16. 
$17,18]$, which is also consistent with our observations. As for large B-cell lymphomas, T-cell markers other than CD5 were expressed more frequently in immunocompromised patients, such as in lymphomas occurring in HIV-positive patients $[14,16]$, pyothorax-associated lymphomas $[15,19$, 20], plasmablastic lymphomas [23, 24, 27, 29], and EpsteinBarr virus (EBV)-positive DLBCLs of the elderly [30], than
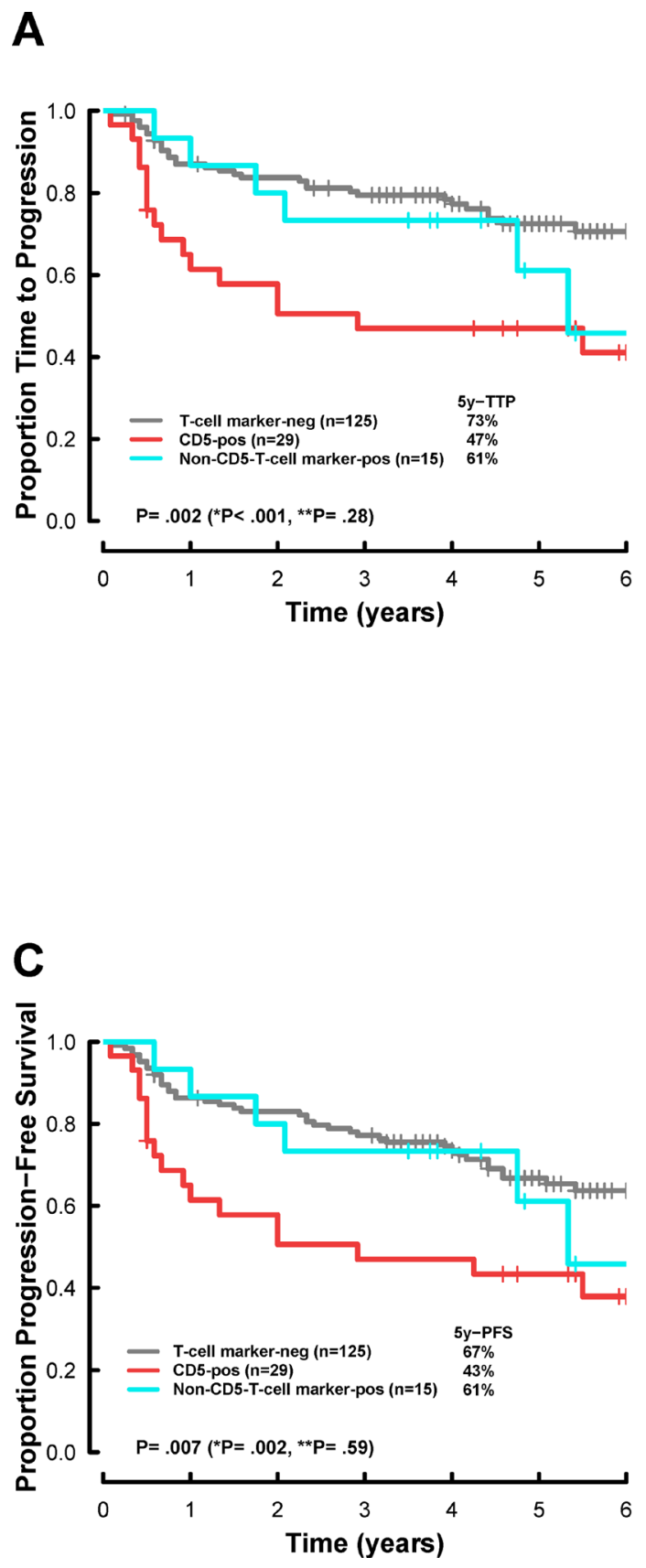

in common DLBCL (Table 1). Most of these non-CD5-T-cell marker-positive large B-cell lymphomas were reported to express CD3 by IHC analysis. In contrast, no CD3-positive cases were observed in previous studies [9-13], or in the present study, where FCM was used for screening.

FCM has a higher sensitivity than IHC for detection of CD5 expression in DLBCL $[3,36]$. Unlike other solid

B
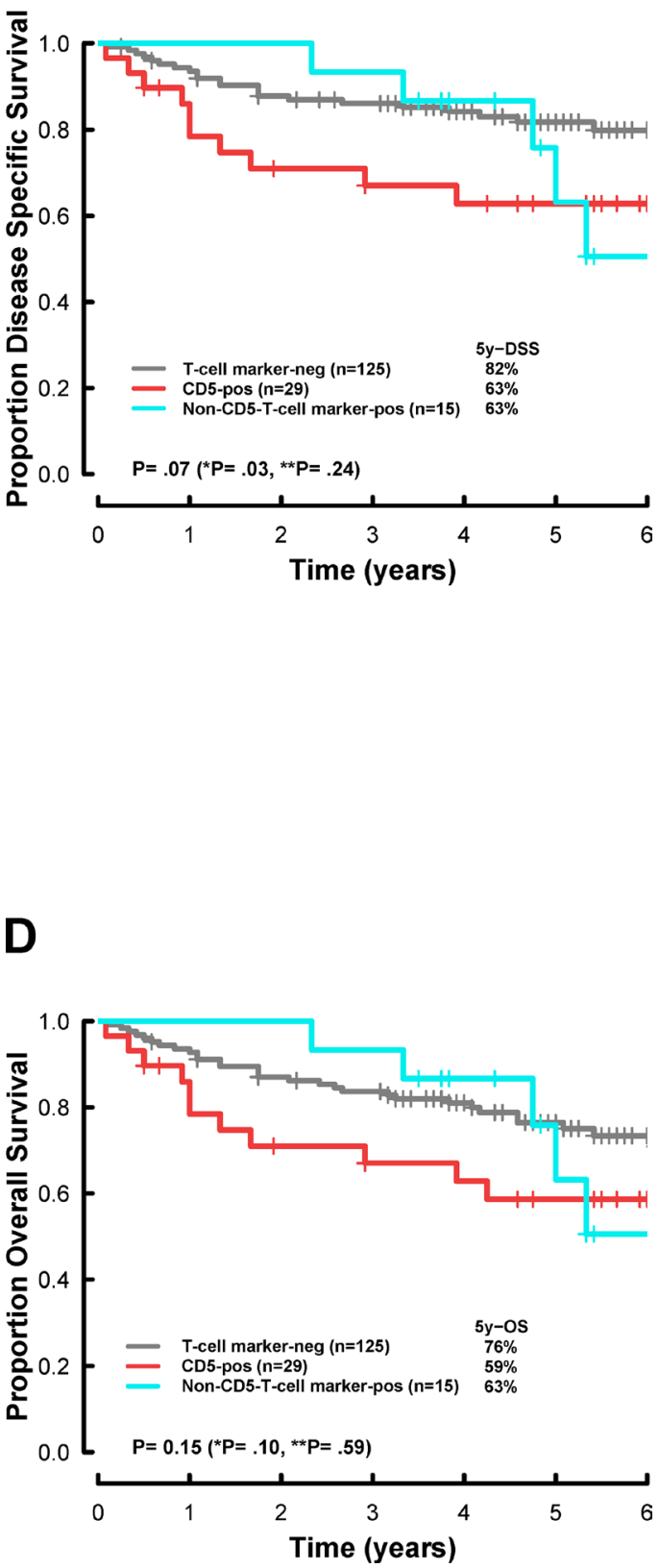

Figure 3: Survival analysis, according to T-cell marker status, in patients with newly diagnosed diffuse large B-cell lymphoma (DLBCL), treated with rituximab plus cyclophosphamide, doxorubicin, vincristine, and prednisone (R-CHOP)-based chemotherapy. Kaplan-Meier curves represent (A) the time to progression (TTP), (B) disease-specific survival (DSS), (C) progression-free survival (PFS), and (D) overall survival (OS). T-cell marker-neg, T-cell marker-negative DLBCL; CD5-pos, CD5-positive DLBCL; Non-CD5-T-cell marker-pos, Non-CD5-T-cell marker-positive DLBCL. *P, CD5-pos vs. T-cell marker-neg; **P, Non-CD5-T-cell marker-pos vs. T-cell marker-neg. $P$ values less than 0.05 were considered statistically significant. 
Table 5: Univariate and multivariate models using PFS and OS of 169 patients with DLBCL

\begin{tabular}{|c|c|c|c|c|c|c|c|c|c|c|c|c|}
\hline \multirow{2}{*}{ variables } & \multicolumn{3}{|c|}{ TTP } & \multicolumn{3}{|c|}{ PFS } & \multicolumn{3}{|c|}{ DSS } & \multicolumn{3}{|c|}{ OS } \\
\hline & HR & $95 \% \mathrm{CI}$ & $\mathbf{p}$ & HR & $95 \% \mathrm{CI}$ & $\mathbf{p}$ & HR & $95 \% \mathrm{CI}$ & $\mathbf{p}$ & HR & $95 \% \mathrm{CI}$ & $\mathbf{p}$ \\
\hline Sex: male & 0.77 & $0.45-1.30$ & 0.32 & 0.78 & $0.48-1.26$ & 0.31 & 1.04 & $0.54-1.98$ & 0.91 & 1 & $0.57-1.78$ & 0.99 \\
\hline IPI: 3-5 & 2.67 & $1.56-4.56$ & $<0.001$ & 2.52 & $1.53-4.15$ & $<0.001$ & 3.48 & $1.82-6.64$ & $\begin{array}{c}< \\
0.001\end{array}$ & 3.08 & $1.73-5.48$ & $<0.001$ \\
\hline non-GC & 1.77 & $1.04-3.01$ & 0.035 & 1.56 & $0.96-2.54$ & 0.072 & 2.02 & $1.05-3.87$ & 0.035 & 1.63 & $0.92-2.90$ & 0.093 \\
\hline CD5 & 2.69 & $1.52-4.78$ & 0.001 & 2.31 & $1.34-3.99$ & 0.003 & 2.08 & $1.01-4.31$ & 0.048 & 1.7 & $0.87-3.35$ & 0.12 \\
\hline CD8 & 1.5 & $0.64-3.49$ & 0.35 & 1.25 & $0.54-2.89$ & 0.61 & 0.61 & $0.15-2.54$ & 0.5 & 0.48 & $0.12-2.00$ & 0.32 \\
\hline CD7 & 1.82 & $0.66-5.05$ & 0.25 & 1.49 & $0.54-4.12$ & 0.44 & 1.01 & $0.24-4.22$ & 0.98 & 0.76 & $0.19-3.15$ & 0.71 \\
\hline $\begin{array}{l}\text { Any T-cell } \\
\text { marker* }\end{array}$ & 2.37 & $1.39-4.05$ & 0.002 & 1.94 & $1.17-3.22$ & 0.01 & 2.07 & $1.08-4.00$ & 0.03 & 1.57 & $0.86-2.88$ & 0.14 \\
\hline \multicolumn{13}{|c|}{ Multivariate } \\
\hline IPI: 3-5 & 2.54 & $1.48-4.37$ & 0.001 & 2.44 & $1.45-4.02$ & $<0.001$ & 3.33 & $1.74-6.38$ & $\begin{array}{c}< \\
0.001\end{array}$ & 3 & $1.68-5.35$ & $<0.001$ \\
\hline non-GC & 1.54 & $0.89-2.67$ & 0.12 & 1.4 & $0.85-2.32$ & 0.19 & 1.81 & $0.93-3.54$ & 0.081 & 1.54 & $0.84-2.73$ & 0.17 \\
\hline CD5 & 2.2 & $1.21-3.99$ & 0.01 & 1.95 & $1.11-3.43$ & 0.021 & 1.59 & $0.75-3.37$ & 0.22 & 1.39 & $0.69-2.80$ & 0.35 \\
\hline
\end{tabular}

*excluded from the multivariate analysis because this group referred to those who were negative for CD5. TTP, time to progression; PFS, progression-free survival; DSS, disease-specific survival; OS, overall survival; HR, hazard ratio; CI, confidence interval; non-GC, non-germinal center.

Table 6: List of antibodies used for immunohistochemistry

\begin{tabular}{lcc}
\hline Antibody & Clone (Source) & Dilution \\
\hline CD2 & AB75 (Novocastra) & $1: 50$ \\
CD3 & F7.2.38 (DAKO) & Ready to use \\
CD4 & 1F6 (Nichirei) & $1: 50$ \\
CD5 & 4C7 (Novocastra) & $1: 20$ \\
CD7 & LP15 (Novocastra) & Ready to use \\
CD8 & C8/144B(Nichirei) & $1: 50$ \\
CD8 $\beta$ & F-5 (SANTA CRUZ) & $1: 100$ \\
CD10 & $56 C 6$ (Novocastra) & $1: 50$ \\
CD20 & L26 (DAKO) & $1: 100$ \\
BCL2 & 124 (DAKO) & $1: 20$ \\
BCL6 & PG-B6p (DAKO) & $1: 50$ \\
MUM1/IRF4 & MUM1p (DAKO) & $1: 100$ \\
MYC & Y69 (Epitomics) & \\
\hline
\end{tabular}

tumors, immunophenotyping of lymphomas is performed not only by IHC but also by FCM. In contrast to IHC, the expression of every representative lineage marker can be analyzed comprehensively by FCM, using a panel of antibodies. However, unlike IHC, which can be done at any time after biopsy, FCM can only be performed immediately after biopsy because it requires live unfixed cells. Therefore, the expression of T-cell markers other than CD5, such as CD2, CD4, CD7, and CD8, has not been broadly investigated in a large case series of B-cell lymphomas. Our FCM screening enabled a sensitive detection of T-cell marker-positive cases, and a good 
concordance between the FCM and IHC results supported the accuracy of FCM screening.

The human CD8 glycoprotein has two subunits, CD $8 \alpha$ and CD8 $\beta$, and the cell surface CD8 is assembled either as an $\alpha \alpha$ homodimer or an $\alpha \beta$ heterodimer, in the native state [37]. CD $8 \alpha \beta$ is broadly expressed on mature peripheral $\alpha \beta$ T cells, whereas CD8 $\alpha \alpha$ is expressed on restricted subsets of cells, including $\gamma \delta \mathrm{T}$ cells, intestinal intraepithelial lymphocytes, natural killer cells, and dendritic cells [38, 39]. Rabinowitz et al. demonstrated that activation of $\mathrm{T}$ cells leads to the appearance of T-cell markers on the surface of neighboring B cells, through direct B- and T-cell interaction [40]. If this transfer mechanism had been operative for our cases, then each $\mathrm{CD}^{+}$neoplastic $\mathrm{B}$ cell in a lymphoma specimen would be positive not only for CD8 $\alpha$ but also for $\mathrm{CD} 8 \beta$, because most of the $\mathrm{CD}^{+} \mathrm{T}$ cells express both $\mathrm{CD} 8 \alpha$ and $\mathrm{CD} 8 \beta$, and they would probably have been transferred together, due to their robust disulfide-linked dimer structures. The majority of our $\mathrm{CD}^{+}$cases $(15 / 18)$, however, were negative for CD $8 \beta$ (Table 2). This observation suggested that most of the $\mathrm{CD}^{+} \mathrm{B}$-cell lymphoma cases harbored CD8 $\alpha \alpha$ not by antigen transfer, but rather by their own potential for abnormal gene expression. Our result was also consistent with a previous report that showed anomalous configuration of $C D 8 A$ in a patient with $\mathrm{CD} 8^{+}$ CLL, subsequently resulting in deregulation of $C D 8 B$ gene expression [41].

In summary, our FCM-based study provided novel information about the proportion of non-CD5T-cell marker-positive B-cell lymphomas, diagnosed according to the current WHO classification, and their prognostic significance in patients with DLBCL. CD5 was reconfirmed as a negative prognostic factor for DLBCL, whereas T-cell markers other than CD5 were shown to have no significance in clinicopathological and survival analyses. The mechanism of T-cell marker expression and the relationship between expression of CD5 and other T-cell markers remain unclear. However, these biological mechanisms should be further explored because of the reproducible prognostic importance of CD5-positivity in DLBCL.

\section{MATERIALS AND METHODS}

\section{Case selection}

We reviewed FCM data of cases that were consecutively diagnosed as mature B-cell lymphomas at the Cancer Institute Hospital, Japanese Foundation for Cancer Research (Tokyo, Japan), between March 2006 and June 2011. Five hundred and one newly diagnosed cases were retrieved, in which abnormal B-cell populations were detected by FCM and confirmed by histopathological examination. These 501 cases of mature B-cell lymphoma included 225 DLBCLs, 134 FLs, 81 MZLs, 17 MCLs, 13
CLLs/SLLs, 6 lymphoplasmacytic lymphomas, 4 Burkitt lymphomas, 2 IVLBCLs, 1 primary mediastinal large B-cell lymphoma, 1 DLBCL associated with chronic inflammation, and 19 low-grade B-cell lymphomas unclassifiable. The diagnostic criteria were based on the 2008 WHO classification.

Of the 225 DLBCL cases, 169 patients who received R-CHOP chemotherapy at our institution were selected to evaluate the prognostic impact of T-cell markers. Patients were excluded from survival analysis if they had a known prior history of an indolent lymphoproliferative disorder or a component of small B-cell lymphoma in the same biopsy specimen. There were no patients with HIV or testicular involvement at diagnosis. We obtained written informed consent from all patients included in the present study.

\section{Flow cytometry analysis}

T-cell marker-positive B-cell lymphoma was defined when one or more T-cell markers (CD2, CD3, CD4, CD5, CD7, and/or CD8) were found by FCM, irrespective of the IHC results. Three-color flow cytometric immunophenotyping was performed, after selecting an appropriate lymphocyte gate on the combination of forward and side scatter plots. The antibodies used were kappa, lambda, CD2, CD3, CD4, CD5, CD7, CD8, CD10, CD11c, CD13, CD19, CD20, CD22, CD23, CD25, CD30, CD45, CD56, TCR $\alpha \beta$, and TCR $\gamma \delta$. The FCM dot plots were specially evaluated, through visual inspection, by two independent pathologists (N.T. and K.T.). Abnormal B-cell populations were determined by the expression of a single immunoglobulin light chain on CD19/CD20 positive cells, or the absence of both. We defined the staining results as follows: negative, similar to the intensity of negative controls (NC); positive, any degree of intensity greater than that of the NC. For T-cell markers determined as positive, we recorded details as follows; equally positive, similar to that of residual normal $\mathrm{T}$ cells; dimly positive, greater than that of $\mathrm{NC}$ and less than the residual normal $\mathrm{T}$ cell. When the distribution of dots extended from positive to negative, we explained the width of the distribution by using "to" as in equal to dim, dim to negative, and negative to $\mathrm{dim}$.

\section{Histopathological analysis}

Formalin-fixed, paraffin-embedded tissue sections were used for histopathological examination. Histopathological images were photographed using an Olympus BX51 microscope equipped with an Olympus UPlan SAPO 40x objective and a JVC KY-F75 digital camera. IHC was performed using a Dako Autostainer with the EnVision+ System-DAB(Dako, Glostup, Denmark), or a BOND-III with the Bond polymer Refine Detection kit (Leica Microsystems, Melbourne, Australia), with antibodies 
for CD5, CD10, CD20, BCL2, BCL6, MUM1, MYC, CD2, $\mathrm{CD} 7, \mathrm{CD} 4, \mathrm{CD} 8$, and CD8 $\beta$ (Table 6). DLBCL cases were classified into GC or non-GC phenotypes, according to the Hans algorithm [42]. For cases positive for non-CD5-Tcell markers by FCM analysis, additional immunostaining of T-cell markers was performed. On IHC analysis, cells were considered positive for T-cell markers when a small population of neoplastic cells was clearly positive. The cutoffs for MYC and BCL2 IHC were $\geq 40 \%$ and $\geq 50 \%$, respectively. The presence of EBV was assessed by in situ hybridization with EBV-encoded small RNA. Fluorescence in situ hybridization (FISH) was performed on formalinfixed, paraffin-embedded sections using three break-apart probes: $B C L 2, B C L 6$, and MYC FISH DNA split signal probes (Dako).

\section{Cytogenetic and gene rearrangement analysis}

G-band karyotyping and gene rearrangement analysis were performed. For cases with availability of sufficient fresh biopsied material, $\operatorname{IgH}$ and $T C R$ gene rearrangements were routinely analyzed by Southern blotting, using the $\mathrm{JH}$ and $\mathrm{C} \beta 1$ probes, respectively.

\section{Statistical analyses}

For survival endpoints, the TTP, PFS, DSS, and OS were calculated from the date of diagnosis, according to Cheson's criteria [43]. The probabilities of TTP, PFS, DSS, and OS were calculated using the Kaplan-Meier method, and distributions were compared by the log-rank test. Univariate and multivariate analyses were performed with the Cox proportional hazard model. Data were analyzed using the R software package and Bioconductor (version 3.3).

\section{ACKNOWLEDGMENTS}

We thank the members of the Ganken Ariake Lymphoma Study Group (GALSG) and Tokyo Lymphoma Study Group (TLSG) for their advice. We also thank Ms. Sayuri Sengoku for her administrative assistance. This study was supported in part by grants from the Japan Society for the Promotion of Science, the Ministry of Health, Labor, Welfare of Japan, the Japan Agency for Medical Research and Development, and the Naito Foundation.

\section{CONFLICTS OF INTEREST}

The authors declare no conflicts of interest.

\section{REFERENCES}

1. Kantor AB. The development and repertoire of B-1 cells (CD5 B cells). Immunol Today. 1991; 12:389-91.
2. Yamaguchi M, Seto M, Okamoto M, Ichinohasama R, Nakamura N, Yoshino T, Suzumiya J, Murase T, Miura I, Akasaka T, Tamaru J, Suzuki R, Kagami Y, et al. De novo CD5+ diffuse large B-cell lymphoma: a clinicopathologic study of 109 patients. Blood. 2002; 99:815-21.

3. Ennishi D, Takeuchi K, Yokoyama M, Asai H, Mishima Y, Terui Y, Takahashi S, Komatsu H, Ikeda K, Yamaguchi M, Suzuki R, Tanimoto M, Hatake K. CD5 expression is potentially predictive of poor outcome among biomarkers in patients with diffuse large B-cell lymphoma receiving rituximab plus CHOP therapy. Ann Oncol. 2008; 19:1921-6.

4. Swerdlow SH, Campo E, Harris NL, Jaffe ES, Pileri SA, Stein H, Thiele J, Vardiman JW. (2008). WHO Classification of Tumours of Haematopoietic and Lymphoid Tissues, Fourth Edition.

5. Porwit A, Borgonovo L, Osby E, Lenkei R, Smith CI, Hammarstrom L. B-cell chronic lymphocytic leukaemia with aberrant expression of CD8 antigen. Eur J Haematol. 1987; 39:311-7.

6. Ghosh K, Sivakumaran M, Wood JK. Aberrant CD8 antigen expression in a patient with $\mathrm{B}$ chronic lymphocytic leukaemia showing unusual disease progression. $\mathrm{Br} \mathrm{J}$ Haematol. 1993; 85:205-6.

7. Mulligan SP, Dao LP, Francis SE, Thomas ME, Gibson J, Cole-Sinclair MF, Wolf M. B-cell chronic lymphocytic leukaemia with CD8 expression: report of 10 cases and immunochemical analysis of the CD8 antigen. $\mathrm{Br} \mathrm{J}$ Haematol. 1998; 103:157-62.

8. Bayo Hanza MC, Palacios MF, Dourisboure R, Slavutsky I, Chena C, Galmarini C, Sarmiento M, de Bracco MM, Scolnik M. CD8 expression in a case of chronic lymphocytic leukemia with trisomy 12. Acta Haematol. 1999; 102:190-5.

9. Islam A, Vladutiu AO, Donahue T, Akhter S, Sands AM, Ambrus JL. CD8 expression on B cells in chronic lymphocytic leukemia: a case report and review of the literature. Arch Pathol Lab Med. 2000; 124:1361-3.

10. Espinosa A, Bjork P, Magnussen K, Moen T, Sorum Y. Aberrant expression of the CD8 antigen in B cell chronic lymphocytic leukaemia. Leuk Lymphoma. 2003; 44:193-6.

11. Schroers R, Pukrop T, Durig J, Haase D, Duhrsen U, Trumper L, Griesinger F. B-cell chronic lymphocytic leukemia with aberrant CD8 expression: genetic and immunophenotypic analysis of prognostic factors. Leuk Lymphoma. 2004; 45:1677-81.

12. Parisi-Duchene E, Mazurier I, Moskovtchenko P. Aberrant CD8 expression in B-chronic lymphocytic leukemia: report of five cases. Acta Haematol. 2006; 115:74-7.

13. Carulli G, Stacchini A, Marini A, Ciriello MM, Zucca A, Cannizzo E, Aliberti S, Demurtas A, Novero D, Calcagno L, Callegari T, Petrini M. Aberrant expression of CD8 in B-cell non-Hodgkin lymphoma: a multicenter study of 951 bone marrow samples with lymphomatous infiltration. Am J Clin Pathol. 2009; 132:186-90. 
14. Hollingsworth HC, Stetler-Stevenson M, Gagneten D, Kingma DW, Raffeld M, Jaffe ES. Immunodeficiencyassociated malignant lymphoma. Three cases showing genotypic evidence of both T- and B-cell lineages. Am J Surg Pathol. 1994; 18:1092-101.

15. Mori N, Yatabe $Y$, Narita $M$, Kobayashi $T$, Asai J. Pyothorax-associated lymphoma. An unusual case with biphenotypic character of T and B cells. Am J Surg Pathol. 1996; 20:760-6.

16. Beaty MW, Kumar S, Sorbara L, Miller K, Raffeld M, Jaffe ES. A biphenotypic human herpesvirus 8-associated primary bowel lymphoma. Am J Surg Pathol. 1999; 23:992-4.

17. Inaba $T$, Shimazaki $C$, Sumikuma $T$, Okano A, Hatsuse M, Okamoto A, Takahashi R, Ashihara E, Hibi S, Sudo Y, Yamagata N, Murakami S, Rin K, et al. Expression of T-cell-associated antigens in B-cell non-Hodgkin's lymphoma. Br J Haematol. 2000; 109:592-9.

18. Kaleem Z, White G, Zutter MM. Aberrant expression of T-cell-associated antigens on B-cell non-Hodgkin lymphomas. Am J Clin Pathol. 2001; 115:396-403.

19. Petitjean B, Jardin F, Joly B, Martin-Garcia N, Tilly $\mathrm{H}$, Picquenot JM, Briere J, Danel C, Mehaut S, AbdAl-Samad I, Copie-Bergman C, Delfau-Larue $\mathrm{MH}$, Gaulard P. Pyothorax-associated lymphoma: a peculiar clinicopathologic entity derived from B cells at late stage of differentiation and with occasional aberrant dual B- and T-cell phenotype. Am J Surg Pathol. 2002; 26:724-32.

20. Tomita S, Mori KL, Sakajiri S, Oshimi K. B-cell marker negative (CD7+, CD19-) Epstein-Barr virus-related pyothorax-associated lymphoma with rearrangement in the JH gene. Leuk Lymphoma. 2003; 44:727-30.

21. Tzankov A, Brunhuber T, Gschwendtner A, Brunner A. Incidental oral plasmablastic lymphoma with aberrant expression of CD4 in an elderly HIV-negative patient: how a gingival polyp can cause confusion. Histopathology. 2005; 46:348-50.

22. Laurent C, Do C, Gascoyne RD, Lamant L, Ysebaert L, Laurent G, Delsol G, Brousset P. Anaplastic lymphoma kinase-positive diffuse large B-cell lymphoma: a rare clinicopathologic entity with poor prognosis. J Clin Oncol. 2009; 27:4211-6.

23. Wang J, Chen C, Lau S, Raghavan RI, Rowsell EH, Said J, Weiss LM, Huang Q. CD3-positive large B-cell lymphoma. Am J Surg Pathol. 2009; 33:505-12.

24. Suzuki Y, Yoshida T, Nakamura N, Kamata H, Kotani S, Ohsaka M, Kajita S, Miyazaki K, Ohtani S, Nakayama M, Horie R, Hayakawa K, Niitsu N, et al. CD3- and CD4positive plasmablastic lymphoma: a literature review of Japanese plasmablastic lymphoma cases. Intern Med. 2010; 49:1801-5.

25. Wang E, Stoecker M. Primary mediastinal (thymic) large B cell lymphoma with aberrant expression of CD3: a case report with review of the literature. Int J Hematol. 2010; 91:509-15.
26. Sangle NA, Agarwal AM, Smock KJ, Leavitt MO, Warnke R, Bahler D, Perkins SL. Diffuse large B-cell lymphoma with aberrant expression of the T-cell antigens CD2 and CD7. Appl Immunohistochem Mol Morphol. 2011; 19:579-83.

27. Sun J, Medeiros LJ, Lin P, Lu G, Bueso-Ramos CE, You MJ. Plasmablastic lymphoma involving the penis: a previously unreported location of a case with aberrant CD3 expression. Pathology. 2011; 43:54-7.

28. Barnhard S, Pai A, Chew HK, Song JY. Richter's syndrome with aberrant CD2 and CD4 expression. J Clin Oncol. 2012; 30:e243-5.

29. Oliveira JL, Grogg KL, Macon WR, Dogan A, Feldman AL. Clinicopathologic Features of B-Cell Lineage Neoplasms With Aberrant Expression of CD3: A Study of 21 Cases. Am J Surg Pathol. 2012; 36:1364-70.

30. Lee M, Cha HJ, Yoon DH, Suh C, Huh J. EBV-positive diffuse large B-cell lymphoma of the elderly with aberrant expression of CD3 and TIA-1. Blood Res. 2013; 48:156-60.

31. Suzuki Y, Yoshida T, Wang G, Aoki T, Katayama T, Miyamoto S, Miyazaki K, Iwabuchi K, Danbara M, Nakayama M, Horie R, Nakamine H, Sato Y, et al. Incidence and Clinical Significance of Aberrant T-Cell Marker Expression on Diffuse Large B-Cell Lymphoma Cells. Acta Haematol. 2013; 130:230-7.

32. Xu-Monette ZY, Tu M, Jabbar KJ, Cao X, Tzankov A, Visco C, Nagarajan L, Cai Q, Montes-Moreno S, An Y, Dybkaer K, Chiu A, Orazi A, et al. Clinical and biological significance of de novo $\mathrm{CD} 5+$ diffuse large B-cell lymphoma in Western countries. Oncotarget. 2015; 6:5615-33. doi: 10.18632/oncotarget.3479.

33. Miyazaki K, Yamaguchi M, Suzuki R, Kobayashi Y, Maeshima AM, Niitsu N, Ennishi D, Tamaru JI, Ishizawa K, Kashimura M, Kagami Y, Sunami K, Yamane H, et al. CD5positive diffuse large B-cell lymphoma: a retrospective study in 337 patients treated by chemotherapy with or without rituximab. Ann Oncol. 2011; 22:1601-7.

34. Yamaguchi M, Nakamura N, Suzuki R, Kagami Y, Okamoto M, Ichinohasama R, Yoshino T, Suzumiya J, Murase T, Miura I, Ohshima K, Nishikori M, Tamaru J, et al. De novo CD5+ diffuse large B-cell lymphoma: results of a detailed clinicopathological review in 120 patients. Haematologica. 2008; 93:1195-202.

35. Lymphoma Study Group of Japanese Pathologists. The world health organization classification of malignant lymphomas in japan: incidence of recently recognized entities. Pathol Int. 2000; 50:696-702.

36. Maeshima AM, Taniguchi H, Nomoto J, Maruyama D, Kim SW, Watanabe T, Kobayashi Y, Tobinai K, Matsuno Y. Secondary CD5+ diffuse large B-cell lymphoma not associated with transformation of chronic lymphocytic leukemia/small lymphocytic lymphoma (Richter syndrome). Am J Clin Pathol. 2009; 131:339-46. 
37. Cole DK, Gao GF. CD8: adhesion molecule, co-receptor and immuno-modulator. Cell Mol Immunol. 2004; 1:81-8.

38. Moebius U, Kober G, Griscelli AL, Hercend T, Meuer SC. Expression of different CD8 isoforms on distinct human lymphocyte subpopulations. Eur J Immunol. 1991; 21:1793-800.

39. Hayday A, Theodoridis E, Ramsburg E, Shires J. Intraepithelial lymphocytes: exploring the Third Way in immunology. Nat Immunol. 2001; 2:997-1003.

40. Rabinowitz R, Massiah E, Hadar R, Schlesinger M. In vitro activation leads to the binding of T-cell markers to the surface of B-lymphocytes. Clin Immunol Immunopathol. 1995; 76:148-54.

41. Attadia V, Alosi M, Improta S, Baccarani M, De Paoli P. Immunophenotypic and molecular genetic characterization of a case of CD8+ B cell chronic lymphocytic leukemia. Leukemia. 1996; 10:1544-50.

42. Hans CP, Weisenburger DD, Greiner TC, Gascoyne RD, Delabie J, Ott G, Muller-Hermelink HK, Campo E, Braziel RM, Jaffe ES, Pan Z, Farinha P, Smith LM, et al. Confirmation of the molecular classification of diffuse large B-cell lymphoma by immunohistochemistry using a tissue microarray. Blood. 2004; 103:275-82.

43. Cheson BD, Pfistner B, Juweid ME, Gascoyne RD, Specht L, Horning SJ, Coiffier B, Fisher RI, Hagenbeek A, Zucca E, Rosen ST, Stroobants S, Lister TA, et al., and International Harmonization Project on Lymphoma. Revised response criteria for malignant lymphoma. J Clin Oncol. 2007; 25:579-86. 